\title{
A Change in Chromosome Number due to Cytomixis in an Interspecific Hybrid of Coix L.
}

\author{
A. B. Sapre and Dayarani S. Deshpande \\ Unit of Cytogenetics, Department of Botany, Marathwada University, \\ Aurangabad-431004, India
}

Accepted December 7, 1985

Cell to cell migration of chromatin is termed as cytomixis and this phenomenon was first recorded in the pollen mother cells (PMCs) of Crocus sativus by Körnicke in 1901 (cf. Brown and Bertke 1969) and later in Oenothera gigas and O. biennis (Gates 1911). In the early stage of anther development PMCs occur in a compact group, the individual meiocytes being closely adpressed. As sporogenous cells they are cytologically very active, initially showing mitotic divisions to increase in number and later undergoing meiosis to produce microspores. These create a very ideal situation for the migration of chromatin, and more so under abnormal and hence in imbalanced constitutions. Other than meiocytes, the phenomenon of cytomixis has been recorded in the root-tip meristems (Jacob 1941, Brown 1947, Sarvella 1958, Tarkowska 1960, 1965 and Bowes 1973), the epidermis of scales and leaves (Tarkowska 1960) and the tapetal cells (Cooper 1952).

Polypolid forms seem to exhibit cytomixis more than their diploid counterparts as shown by triploids and tetraploids of sugarbeet (Semyarkhina and Kuptsou 1974). However, in Prunus while diploids, tetraploids and hexaploids are normal, natural or artificial triploid hybrids involving these polyploids are cytomictic (Salesses 1970). Cytologically and hence physiologically and biochemically imbalanced plants like haploids, triploids, aneuploids, hybrids and apomicts show cytomixis more often than normal cytogenetically balanced and established plants (Percival 1930, Kihara and Lilienfeld 1934, Nandi 1937, de Nattoncourt and Grant 1964, Gottschalk 1970 and Salesses 1970). There are sporadic reports on the occurrence of cytomixis in some individual plants even from a normal population (Bell 1964, Bhandari et al. 1969, Omara 1976, Sapre 1978, Chauhan 1981). Cytomixis may also occur when plants are treated with various chemicals like lauryl alcohol (Bobak 1966), herbicide like trifluraline (Bobak and Herich 1978) or EMS (ethyl methane sulphonate), a chemical mutagen (Datta and Biswas 1984).

In spite of the fact that the phenomenon of cytomixis has been so widespread and studied in sufficient detail, both under light as also electron microscope references to cytomixis are rare in the recent texts and reviews on cytology. In the present communication, a change in the chromosome number due to cytomixis in an interspecific hybrid of Coix L. is reported.

\section{Materials and methods}

The genus Coix L. belongs to the tribe Maydeae of the family Poaceae and it is represented by three species growing wild in India (Bor 1960). Spontaneous interspecific hybrids between aneuploids of $C$. gigantea $(2 n=18-24)$ and $C$. aquatica $(2 n=10)$ having chromosome numbers of $2 n=14,2=15$ and $2 n=16$ were isolated and studied cytologically (Sapre et al., 1985). When these hybrids were grown in association with their parents and allowed to open-pollinate, a series of plants with chromosome numbers from $2 n=10$ to $2 n=21$, having a mixture of aquatica and gigantea chromosomes were isolated from this outcrossed progeny (Sapre and Deshpande, 1986). Routine acetocarmine ( $1 \%$ ) squashes of young anthers from fixed male racemes ( 1 : 
3 acetic-alcohol) of one of the chromosomal variants with $2 n=16$ chromosomes showed cytomixis during meiosis in some of the PMCs. The photomicrographs showing cytomixis in the present paper were taken from the temporary squash preparations and the negatives are deposited with the Cytogenetics Unit of the Botany Department.

\section{Results}

There being considerable karyotypic differences between the gigantea (chromosomes smaller and karyotype asymmetric) and aquatica (chromosomes larger and karyotype symmetric) genomes, the chromosomes of the two species could be easily identified in the hybrids as also chromosomal variants (Sapre and Deshpande 1986).

As ascertained from the several PMCs observed at diakinesis, the present plant with $2 n=$

Table 1. Frequency of cytomictic PMCs in C. gigantea $\times$ C. aquatica hybrid

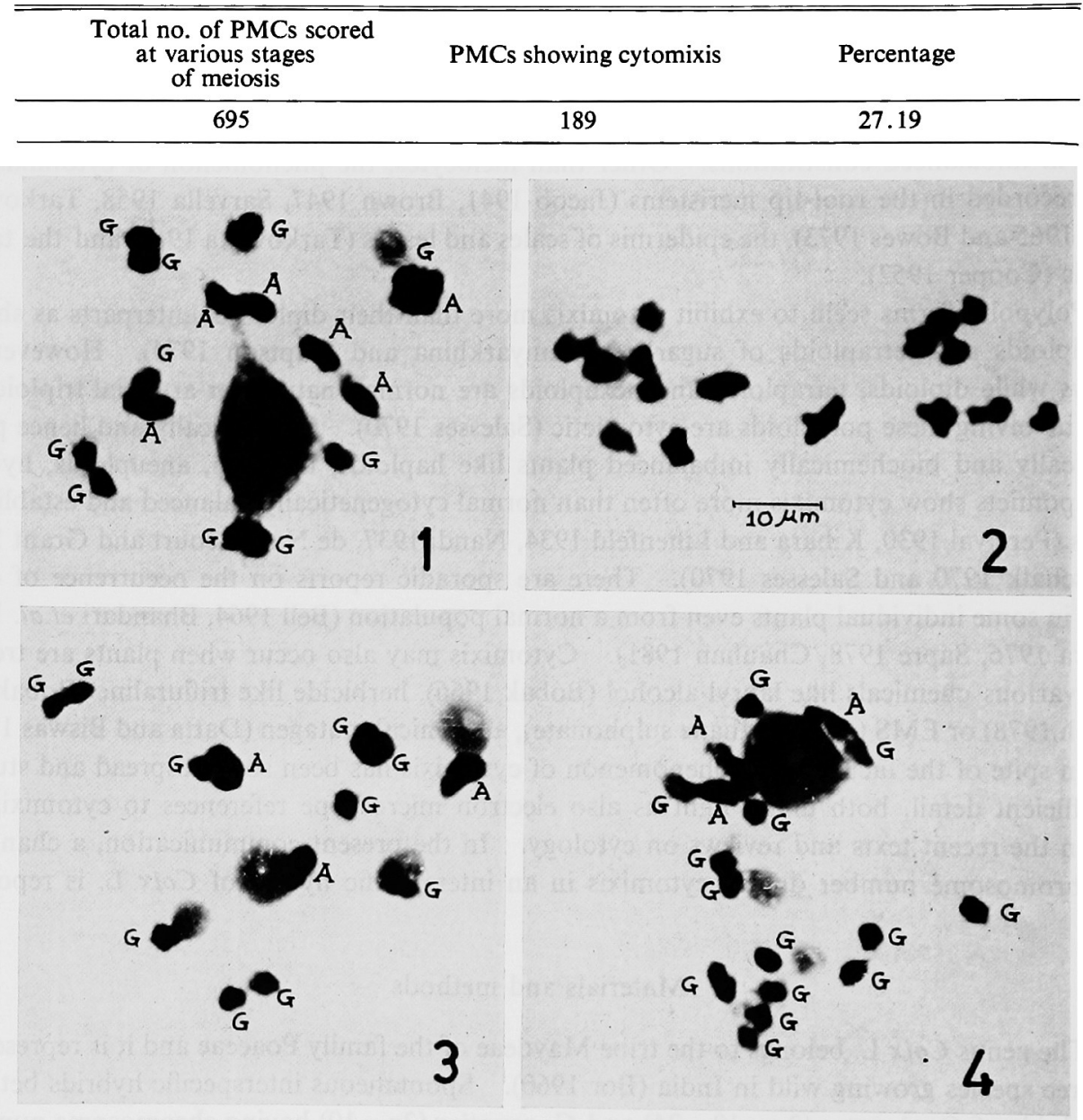

Figs. 1-4. Normal and chromosomally variant PMCs. 1, hybrid showing $2 \mathrm{n}=16$ chromosomes, $7 \mathrm{II}+2 \mathrm{I}$, at diakinesis $(10 \mathrm{G}+6 \mathrm{~A})$. Note the heteromorphic bivalents $(\mathrm{G}-\mathrm{A}) .2$, a rare anaphase-I showing equal distribution of chromosomes (8:8). 3, PMC showing 13 chromosomes, $4 \mathrm{II}+5 \mathrm{I}$, at diakinesis $(10 \mathrm{G}+3 \mathrm{~A})$. Note the loss of three aquatica chromosomes. 4, PMC with $2 \mathrm{n}=17$ chromosomes, $5 \mathrm{II}+7 \mathrm{I}$, at diakinesis $(14 \mathrm{G}+3 \mathrm{~A})$. Note the loss of three aquatica but addition of four gigantea chromosomes. Note: $\mathrm{G}$ and $\mathrm{A}$ represent $C$. gigantea and $C$. aguatica chromosomes, respectively. 
16 included 10 chromosomes from gigantea and six chromosomes from the aquatica genomes. The two species being phylogenetically closely related, their chromosomes showed regular intergenomic pairing although bivalents and multivalents were usually heteromorphic (Fig. 1; Sapre and Deshpande 1986). Univalents in different number were frequently recorded (Figs. 3,4 ) and they were usually the smaller chromosomes from the gigantea genome (Fig. 4). In large number of PMCs, chromosomes showed sticky configurations, with the nucleolus breaking up into smaller bits. At anaphase-I variable number of univalent laggards were noted in most of the PMCs resulting in unequal chromosomes at the two poles. However, equal segregation (8-8) of chromosomes was not uncommon (Fig. 2). Some PMCs (Table 1) prominently showed displacement of the chromosomal mass from its nearly central position to the periphery (Fig. 5). The chromosomal masses of the closely placed PMCs moved towards each other (Fig. 6) as though in preparation to chromatin migration and as if between them existed some attractive force. The chromosomal masses in these adjacent PMCs came very close to each other remaining separated merely by the thin bounding membranes of the respective meiocytes. Subsequently, chromosomes from one PMC moved into another effecting cytomixis. When more than two PMCs were involved in the cytomixis, a kind of relay transfer of chromatin was observed (Fig. 7). However, it was rather difficult to say with certainty whether the chromosomal masses migrated only in one direction.

In none of the PMCs observed so far complete transfer of chromatin was recorded (or else, some empty PMCs could have been noted). The partial migration of chromatin resulted in PMCs that deviated from the original chromosome number of $2 n=16$ to $2 n=13$ (Fig. 3) and $2 n=17$ (Fig. 4). In the PMCs with $2 n=13$ there were 10 chromosomes from gigantea and three chromosomes from aquatica genomes clearly showing a loss of three aquatica chromosomes from the original constitution of $2 n=16(10+6)$. PMCs with $2 n=17$ had 14 chromosomes from gigantea and three chromosomes from aquatica genomes showing addition of four chromosomes from gigantea genome but loss of three aquatica chromosomes. Thus due to cytomixis not only there was a numerical deviation from the original chromosome number $(2 \mathrm{n}$ $=16$, but also a quantitative change in regard to the number of gigantea and aquatica chromosomes. Chromosomal migration was evident at diplotene-diakinesis (Fig. 7) and at anaphase-I (Figs. 6, 8) and along with them also moved the nucleolus/nucleolar bits (Fig. 7). Pollen fertility was very poor and most of the pollen were empty and deformed. Ciox is an open pollinated genus and the present plant $(2 n=16)$ produced no seeds although it was surrounded by many normal plants of both the parental species, indicating that even the female gametes on it were probably nonviable. This gametic sterility was not solely due to cytomixis but chromosomal stickiness, irregular pairing and segregation, large number of laggards etc. led to irregularities during meiosis producing nonviable male (as also perhaps female) gametes.

\section{Discussion}

\section{Cytomixis, a neglected phenomenon}

The migration of chromatin, nucleus, nucleolus, nucleolar bits, individual chromosome, group(s) of chromosomes, whole spindles etc. from one cell to another that is close by has been reported and studied in several plants belonging to diverse families (Bell 1964, Maheshwari 1950). In addition to meiocytes, cytomixis has also been reported in apical meristems, epidermal cells of scales and leaves, tapetal cells, and cells of nucellus and integuments. The phenomenon of cytomixis occurs both during mitosis and meiosis and it has been studied under light as also electron microscopes. In spite of this, cytomixis has remained a neglected cytological event with no or only a passing reference in the recent texts on cytology. As a result, the 
phenomenon has not found any significant place in under- and post-graduate teaching programmes, at least in our country. There are various reasons for this neglect and some of these are discussed here.

Cytomixis is of comparatively rare occurrence and has been more often noted among hy-

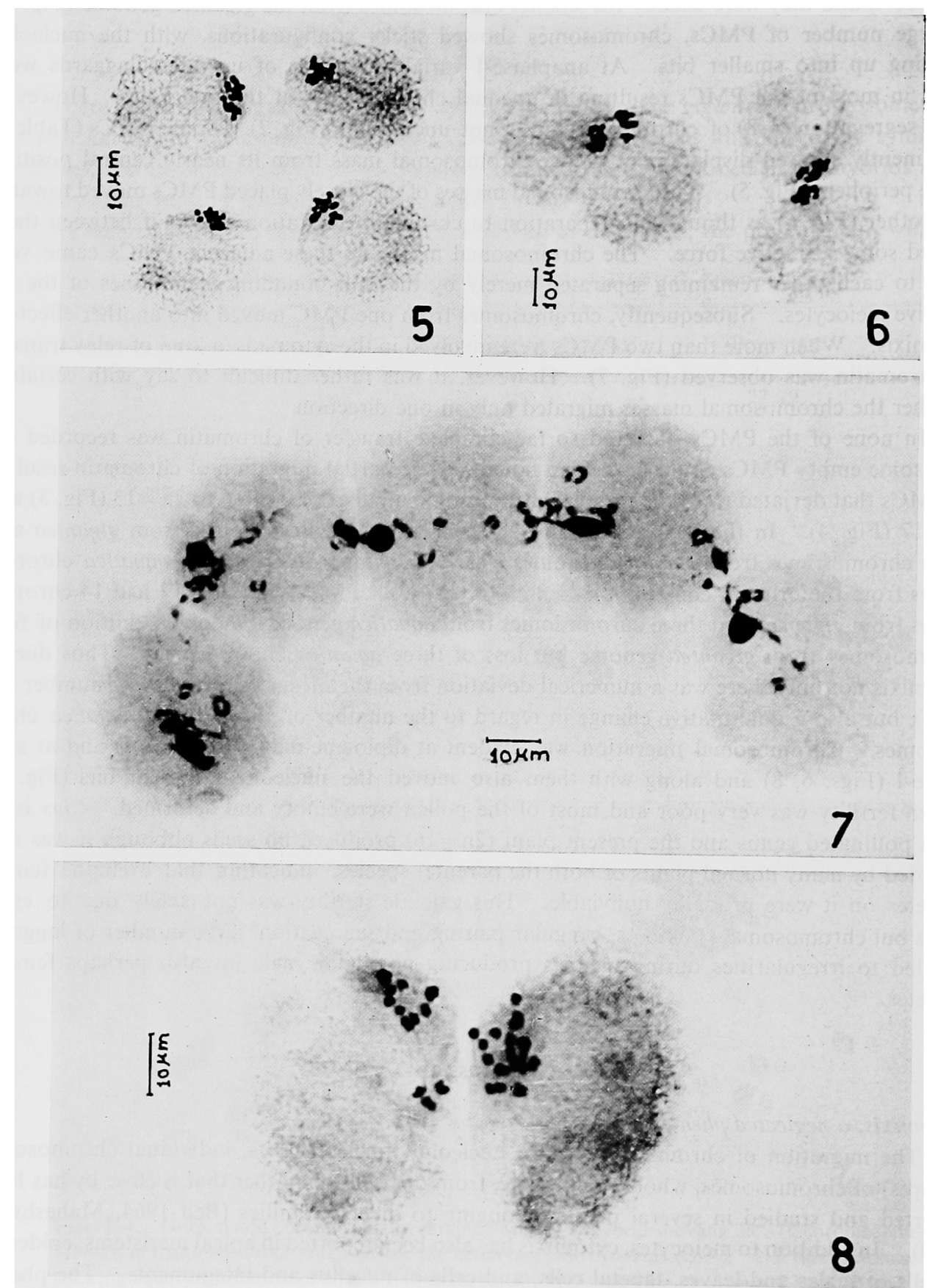

Figs. 5-8. Stages in the cytomixis. 5, migration of chromatin towards periphery of the PMC thereby increasing chances of cytomixis. 6, PMCs closing-in to ease chromatin migration. 7, movement of chromosomes and nucleoli in a chain of five PMCs at diakinesis. 8, two PMCs with unequal chromosomes at anaphase-I, also note unequal distribution. 
brids and cytogenetically imbalanced plants-the latter themselves are poorly studied thoroughly, repeatedly and through different seasons.

Cytomixis usually leads to abnormal PMCs/cells which rarely or never show any viability, it being thus a dead-end either in development or in differentiation of cells, tissues or organs. The cytological aberrations produced at the end of cytomixis are more often non-hereditary and hence of little significance.

The cause(s), if any, of cytomixis is also not clearly understood. There is no record so far where the whole plant is reported to be cytomictic, the reports have always been only of partial occurrence. It is not known whether the control is genetical, physiological, biochemical or environmental. Hybridization experiments using cytomictic character have not been attempted to study its mode of inheritance. The phenomenon does not occur with any consistency; sometimes polyploids show it, but not their diploid counterparts (Semyarkhina and Kuptsou 1974) or it may be vice versa (Salesses 1970). Again, although it is expected to be more prevalent in hybrids, not all hybrids show it. Among the several interspecific hybrids in Coix with various permutations and combinations of chromosomes from the two species (and hence cytologically highly imbalanced) studied by us in this laboratory (Sapre and Deshpande, in press and our unpublished data), hardly one or two hybrids have exhibited cytomixis, and that too only partially.

Cytomixis as a manifestation of pathological changes (Bobak and Herich 1978, Morisset 1978) and faulty fixation (Woodworth 1931, Linnert 1955, Takats 1959) have been suggested. However, evidence for either is lacking, and literature reveals that normal and healthy plants also show cytomixis (Bell 1964, Bhandari et al. 1969, Omara 1976, Sapre 1978, Chauhan 1981). Bobak (1966), Bobak and Herich (1978) and Datta and Biswas (1984) have recorded cytomixis in chemically treated plant cells. If cytomixis was to be due to faults in the fixation or fixing procedures, it fails to explain why only a few cells should show this phenomenon. And if it were to be an artefact arising out of improper fixation, this could have been a very promising method to arificially induce cytomixis; this has not been done by anyone to the best of our knowledge.

Woodworth (1931) attributes cytomixis to the extra pressure applied during smear preparations of anthers. Smear as a cytological technique is outdated and has been effectively replaced by the squash technique. It is quite likely that squeezing pollen sacs between slides in smear preparations would possibly lead to cytomixis since some PMCs are bound to get badly crushed while being drawn into a monolayer. Also, chromosomal configurations get disfigured due to the horizontal pull applied during smear procedures.

In a squash preparation, PMCs can be handled with lot of care and they can be observed under the microscope in a drop of stain even without applying a coverslip. In the present study, some of the PMCs have clearly shown cytomixis in squashes prior to applying any pressure on the coverslip. Holding the slide between a pad of blotting paper and moderately pressing vertically with a finger tip just to flatten the cells to bring the micropreparation in one focus is not likely to induce cytomixis. In fact, leaving the microprepartions for sometime after the squash is made hardens the PMCs so much that any amount of vertical pressure can do no harm to the micropreparation, let alone causing migration of cell contents. However, it is experienced in some plants, that if the PMCs are brittle, and if they are squashed without prior fixation, artefacts simulating cytomixis are common especially when the chromosomes are sticky; but such distortions can be easily made out with little experience.

\section{Place of cytomixis}

It appears that any compact group of meristematic cells is highly potent to express the phenomenon of cytomixis. Earlier it was thought to occur only among PMCs undergoing 
meiosis. However, somatic cells undergoing repeated mitoses at different sites in plants have now shown this phenomenon. It has been demonstrated by Bobak and Herich (1978) that cytomixis during mitosis does not in any way differ from that occurring in PMCs during meiosis. The amount of chromatin that migrates also varies a great deal, and may be interphase nucleus, single chromosome or group of chromosomes, whole of the spindle apparatus with all the chromosomes or nucleolus may move from one cell to another. When cytomixis is complete, the donor cell becomes empty and the recipient nearly doubles in its contents (Gottschalk 1970). Cytomixis has been reported in cells undergoing premeiotic mitoses (de Nattoncourt and Grant 1964) and the phenomenon is considered to continue in the meiotic prophase. Nuclear migration in PMCs prior to the onset of meiosis has been reported in Trilobachne cookei (Sapre 1978). Meiotic prophase, which is composed of subphases, seems to be the most frequently reported stage at which chromatin migration takes place (Kihara and Lilienfeld 1934, Matsuura 1935, Bopp-Hassenkamp 1959, Pradhan and Sen 1971, Chauhan 1981, Singh et al. 1981). However, this is not the rule and even at metaphase-I (Kamara 1960), at metaphase-I and anaphase-I (Sarvella 1968, present report), during interkinesis (Gates and Latter 1927), at telophase-II (Stebbins 1932), and at the close of meiotic divisions (Gelin 1934) chromatin migration has been reported. Thus, cytomixis may occur at any place where active dividing cells are present in a group and at any stage of mitosis and/or meiosis (Gottschalk 1970).

\section{Consequences of cytomixis}

The result of cytomixis is obviously a change in the amount of chromatin and/or number of chromosomes in the cells involved. Depending on the degree of cytomixis, cells from aneuploid (Percival 1930, Nandi 1937, Sarvella 1958, present report) to polyploid (Gottschalk 1970) constitutions may result. In any case, it is rather doubtful if the products of cytomixis are viable and are able to function producing a variant in the following generation, if it is gametic or a chimeral sector, if it is somatic. In all probability, the chromosomally abnormal microspores produced as a result of cytomixis are sterile and non-functional. Being aneuploid in nature they would not be able to stand in competition with the normal pollen even if they are functional.

\section{Nature of migration}

Although meiocytes or somatic cells in a group are closely placed, they are separated by their walls and are perfectly independent units. Plasmodesmatal connections are known to join PMCs with each other and it is through these thin strands that a close synchrony in meiotic stages is established and maintained. It was argued in the past that the plasmodesmatal connections enlarge allowing movement of cell contents. However, it has been shown that cytomixis occurs through channels that arise de novo in the intervening walls (Heslop-Harrison 1964). The existence of communicating channels has been suggested by Baquar and Husain (1969) and Risueino et al. (1969), and the cytoplasmic links between the PMCs have been shown by Gottschalk (1970) and Datta and Biswas (1984). In the present report, however, no cytoplasmic channels were seen and chromosomal masses in the adjacent PMCs, having come closer simply moved from one PMC to another crossing cellular boundaries as if they did not exist (Fig. 7).

\section{Is cytomixis by chance?}

The cause(s) of cytomixis is not known since nothing beyond simply noting the migration of chromatin, partly or fully, during meiosis or mitosis, and in normal or cytogenetically imbalanced plants has been reported. It is difficult to logically conclude and establish any cause and effect relationship concerning this phenomenon. However, in the present report the ec- 
centric position taken by the chromatin in some PMCs and the movement of chromosomal masses towards each other ultimately meeting at a common point (as if attracting each other) gives an impression that cytomixis is not by chance, at least in the present plant material. This directed movement of chromatin certainly increases chances of chromosomal mixing and although force(s) controlling this movement is not known, a question remains to be answered; can this all be without any purpose?

\section{Summary}

A change in the chromosome number of some PMCs in an interspecific hybrid of Coix $\mathrm{L}$. (C. gigantea $\times$ aquatica, $2 \mathrm{n}=16$ ) through cytomixis is reported. In the cytomictic PMCs the chromosomal changes are both quantitative, having $2 n=13$ and $2 n=17$ chromosomes instead of the usual $2 n=16$ and qualitative, having variable number of parental chromosomes instead of the usual $10+6$ gigantea and aquatica combination. Causes, places, types, consequences and nature of cytomixis are discussed. It is argued that in the PMCs, the displacement of chromatin from its nearly central position towards periphery, as if acted upon by some force and in preparation to migration, cannot be without any purpose, the latter though as yest not clear to us.

\section{Acknowledgements}

We are grateful to Prof. S. T. Tilak for facilities and one of us (DSD) also thanks the University Grants Commission for a fellowship.

\section{References}

Baquar, S. R. and Husain, S. A. 1969. Cytoplasmic channels and chromatin migration in the meiocytes of Arnebia hispadissima (Sieb.) DC. Ann. Bot. 33: 821-831.

Bell, C. R. 1964. Cytomixis in Tauschia nudicaulis Schlecht (Apiaceae). Cytologia 29: 396-398.

Bhandari, N. N., Tandon, S. L. and Jain, S. 1969. Some observation on the cytology and cytomixis in Canavalia DC. Cytologia 34: 22-28.

Bobak, M. 1966. The effect of lauryl alcohol on mitotic index on defects of cell division and on cytomixis. Caryologia 19: 369.

- and Herich, R. 1978. Cytomixis as a manifestation of pathological changes after the application of trifluraline. The Nucleus 21(1): 22-26.

Bopp-Hassenkamp, G. 1959. "Cytomixis" im electronenmikroskopischen Bild. Exptl. Cell Res. 18: 182-184.

Bor, N. L. 1960. Grasses of Burma, Ceylon, India and Pakistan. Pergamon Press, New York.

Bowes, B. G. 1973. Note on apparent case of cytomixis in the root apex of Allium cepa. Cytologia 38: 125-129.

Brown, M. S. 1947. A case of spontaneous reduction of chromosome number in somatic tissue of cotton. Am. J. Bot. 34: 384-388.

Brown, W. V. and Bertke, E. M. 1969. Textbook of Cytology. The C. V. Mosby Co., St. Louis.

Chauhan, A. K. S. 1981. Cytomixis in Papaver rhoeas. Proc. 3rd. All India Cong. Cytol. and Genet. 3: 309312.

Cooper, D. D. 1952. The transfer of deoxyribose nucleic acid from the tapetum to the microsporocytes at the onset of meiosis. Am. Nat. 86: 219-229.

Darlington, C. D. and Janaki Ammal, E. K. 1945. Chromosome Atlas of Cultivated Plants. London, pp. 397.

Datta, A. K. and Biswas, A. K. 1984. Cytomixis and a trisomic in Nigella sativa L. Cytologia 49: 437-445.

Gates, R. R. 1911. Pollen formation in Oenothera gigas. Ann. Bot. 25: 909-940.

- and Latter, J. 1927. Observations on the pollen development of two species of Lathraea. Jour. Roy. Micros. Soc. 47: 209-224.

Gelin, O. E. V. 1934. Embryologische und cytologische Studien in Heliantheae-Coreopsidinae. Acta Horti Bergiani. 11: 99-128.

Gottschalk, W. 1970. Chromosome and nucleus migration during microsporogenesis of Pisum sativum. The Nucleus 13: 1-9. 
Heslop-Harrison, J. 1964. Pollen physiology and Fertilization. H. P. Linskens (Editor). North Holland Publishing Co. Amsterdam.

Jacob, K. T. 1941. Certain abnormalities in the root tips of cotton. Curr. Sci. 10: 174-175.

Kamara, O. P. 1960. Chromatin extrusion and cytomixis in pollen mother cells of Hordeum. Hereditas. 46: 592-600.

Kihara, H. and Lilienfeld, F. 1934. Kerneinwanderurng und Bildung syndiploider Pollenmutterzellen bei dem F-Bastard Triticum aeqilopoides $\times$ Aegilops squarrosa. Jap. J. Genetics 10: 1-28.

Linnert, G. 1955. Cytologische Grundlagen für Sterilitätserscheinungen in der Gattung Salvia. Der Züchter 25: 237-241.

Maheshwari, P. 1950. An Introduction to the Embryology of Angiosperms. McGraw-Hill, N.Y.

Matsuura, H. 1935. A cytological study on Phacellanthus tubiflorus Sieb. et Zucc. I. J. Fac. Sci. Hokkaido Imp. Univ. S. V. 3: 169-187.

Mantu, De and Sharma, A. K. 1983. Cytomixis in pollen mother cells of an apomictic ornamental Ervatamia divaricata (Linn.) Alston. Cytologia 48: 201-207.

Morriset, P. 1978. Cytomixis in the pollen mother cells of Ononis (Leguminosae). Can. J. Genet. Cytol. 20: 383-388.

Nandi, E. K., 1937. Cytological investigations of rice varieties. Cytologia 8: 277-305.

de Nattancourt, D. and Grant, W. F. 1964. La cytogénétique de Lotus (Leguminosae) III. Un cas de cytomixis en hydride interspécifique. Cytologia 29: 191-195.

Nirodi, N. 1955. Studies on Asiatic relatives of maize. Ann. Mo. b. Gdn. 42: 103-130.

Omara, M. K. 1976. Cytomixis in Lolium perenne. Chromosoma 55: 267-271.

Percival, J. 1930. Cytological studies of some hybrids of Aegilops sp. $\times$ wheats and of some hybrids of between different species of Ageilops. Jour. Genet. 22: 201-278.

Pradhan, K. and Sen, S. 1971. Cytomixis in jute (Corchorus olitorius L.). Proc. First All India Cong. Cytol. and Genet. (Suppl.) 1: 265-269.

Risueno, M. C., Gimenez-Martin, G., Lopez-Saez, J. F. and R. Garcia, M. I. 1969. Connexion between meiocytes in plants. Cytologia $34: 262-272$.

Salesses, G. 1970. Cytomictic phenomenon in the triploid hybrids of Prunus. Consequent genetic possibilities. Ann. Ameliorplantes (Paris) 20(4): 383-388.

Sapre, A. B. 1978. Cytomixis in Trilobachne cookei (Stapf) Sehenck (Poaceae). Ind. J. Bot. 1 (1/2): 29-33.

-, Barve, S. S. and Deshpande, D. S. 1985. Cytological report on the spontaneous interspecific hybrids in Coix $\mathbf{L}$. involving aneuploids. Cytologia 50: 655-661.

- and Deshpande, D.S. 1986. A chromosomal range in the interspecific hybrids and the hybrid derivatives of Coix L. (Poaceae). Curr. Sci. 55: 363-364.

Sarvella, P. 1958. Cytomixis and the loss of chromosomes in meiotic and somatic cells of Gossypium. Cytologia 23: $14-24$.

Semyarkhina, S. Ya. and Kuptsou, M. S. 1974. Cytomixis in various forms of sugarbeet. Vests I AN BSSE. Ser. biyal. 4: 43-47.

Singh, C. B., Gaur, V. K. and Gaur, P. M. 1981. Mechanism of chromosome migration during microsporogenesis in plants (hexaploid triticale). Proc. 3rd All India Cong. Cytol. and Genet. 3: 501-504.

Stebbins, G. L. Jr. 1932. Cytology of Antennaria II. Parthenogenetic species. Bot. Gaz. 94: 322-345.

Takats, S. T. 1959. Chromatin extrusion and DNA transfer during microsporogenesis. Chromosoma 10: 430-453.

Tarkowska, J. 1960. Cytomixis in epidermis of scales and leaves and in meristems of the root apex of Allium cepa L. Acta. Soc. Bot. Polon. 29: 149.

- 1965. Experimental analysis of the mechanism of cytomixis I. Cytomixis in vegetative tissues. Acta Soc. Bot. Polon. 34: 27-44.

Venkateswarlu, J. and Chaganti, R. S. K. 1973. Job's Tears. Techn. Bull. No. 44, Indian Council Agri. Res., New Delhi. pp. 1-54.

Woodworth, R. H. 1931. Cytomixis. J. Arnold Arbor. Harvard Univ. 12: 23-25. 